\title{
Structural solution of the horizontal joint of floor slabs in girderless frame
}

\author{
Juliya Mironova*1[0000-0001-6329-132] \\ ${ }^{1}$ Kazan State University of Architecture and Engineering, 420043 Kazan, Russia
}

\begin{abstract}
Despite the widespread use of monolithic construction, precast concrete remains in demand in the construction of residential and administrative buildings. Regardless of the advantages in technology and the quality of work, it is necessary and appropriate to modernize the existing design solutions, which allows you to simplify and speed up the technological operations during construction. Moreover, in the construction of complex nodes and joints, the qualification of workers is important, so simplifying the work without losing the quality of construction and ensuring strength, stability and durability is an important task. This problem can be solved by using modern embedded parts in the joints that do not require welding and other complex technological operations. In this paper, a constructive solution of the horizontal joint of the floor slabs located in the zone of action of minimal forces is proposed on the example of a girderless frame. The purpose of the study is to determine the stress-strain state of the proposed structural solution of the horizontal joint of floor slabs using loopshaped embedded parts «PFEIFER» and to develop recommendations for determining the shear compliance. Based on the analysis of the results of numerical modeling, the features of the stress-strain state of the joint during shear operation are revealed. The results obtained can be used in the design of buildings with precast-monolithic ringless frames, in the modernization of existing standard solutions of precast-monolithic frames, as well as other load-bearing systems made of precast concrete.

Keywords. Multi-storey buildings, girderless frame, horizontal joint of floor slabs, loop-shaped embedded parts, welded joint, shear compliance.
\end{abstract}

\section{Introduction}

Today, the technology of monolithic reinforced concrete is widely used for the construction of buildings for various purposes, however, precast concrete does not give up its positions. Its main advantages are cost-effectiveness, quick construction, a high degree of control during production at the factory, the use of standard solutions, and others. Taking into account these advantages, as well as the relative simplicity of the technology and the quality of work, the construction of frame buildings for residential and administrative purposes from precast concrete elements remains relevant [1-3], but it is necessary and expedient to modernize existing design solutions $[4,5]$, which allows to simplify and speed up technological operations during construction [6-8]. The weak point of precast concrete is the

${ }^{*}$ Corresponding author: yul.mironova2018@mail.ru 
connection of elements. The problem of choosing the optimal solution of the joint, ensuring its operation on vertical and horizontal loads is relevant. Attempts are being made to create durable, suitable for normal function, strong and technological joints [9], which will have a positive impact on the overall stability of precast concrete buildings [10]. In [11], for example, a new solution for the joints of a column and a plate in a girderless frame is proposed, which simplifies technological operations and optimizes the stress-strain state of the joint and the frame as a whole.

In Russia, one of the frames used is the ringless frames according to the UIKSS and CUB systems, the peculiarity of which is the rigid fixing of the floor slabs on the columns and the hinged connection between them due to the tamping of the keys $[12,13]$. The dimensions of the floor slabs are designed so that the joints of the panels are located in the zones of zero bending moments. The structural solution of the horizontal joint of floor slabs in the construction of ringless frames is the joint of the design of Academician G.P. Perederia, which is also used in the design of bridge spans. However, this classic solution gives certain difficulties during installation. Many works of Russian and foreign authors are devoted to the modernization of this joint, finding the optimal solution for the placement of reinforcement, simplifying the installation technology, saving materials, determining the strength and deformation characteristics.

The main purpose of horizontal and vertical joints between panels or slabs is the perception of shear forces [14]. Experimental studies are limited to determining the optimal placement of reinforcement in the joints between wall panels, bridge plate joints [15-17], as well as issues of concrete work in the joint, issues of adhesion of panel concrete and butt concrete [18]. In addition, the issues of shear strength are also considered in relation to the construction of multi-layer wall panels [19-21], data on the flexibility of the reinforcement in the joints, the influence of its position on the nature of the destruction of the joints and the connected panels, the destructive loads are obtained. The obtained data can be partially applied to the joints of building elements, for example, when studying the influence of the number and location of embedded parts and fittings in the joints, studying the nature of joint failure during shear [22, 23].

It is known that buildings made of precast concrete have sufficient resistance to seismic loads, under the influence of which the main task of the joints is to work in shifts. Many works are devoted to determining the shear characteristics of various structural joints [24-26]. In [27], an analysis of joint damage after an earthquake was carried out in order to determine the weaknesses and strengths of each type of joint and further develop a design solution for joints with optimal strength and deformation characteristics.

The issues of the durability of buildings as a whole [28] and the residual load-bearing capacity of joints and their reinforcement [29-31] are also of great importance. It is noted that to determine the effective method of reinforcement, data on the strength and flexibility of the joint are necessary not only at the design stage, but also taking into account various aspects of the operation of the object. Methods of reinforcement with carbon fiber, taking into account the direction of shear flows, fine-grained concrete, and their combination are proposed. Thus, each proposed structural solution of joints should be tested for changes in strength and compliance, and analytical expressions for determining these characteristics would reflect the actual stress-strain state.

Modernization of structural solutions of joints, proposed by scientists and engineers, is reduced to minimizing costs during construction, reducing the material consumption of the joint, increasing strength characteristics, reducing deformability. The possibility of using reinforcement with a shorter overlap length [32, 33], continuous reinforcement [34], reducing the joint width [35], using new anchor designs [6], as well as new forms of rods and dowels $[24,36]$ is widely discussed. Separately, we can distinguish solutions based on the use of welded loop-shaped embedded parts in the joints [37,38], for which multi-factor experiments 
established the bearing capacity for shear and tension, determined the destructive loads, proposed models of the joint action of the moment and the tensile force, described the schemes of crack formation and destruction. A number of studies are devoted to the work of vertical joints of wall panels on shear, in particular, the use of a nonlinear deformation model for determining the bearing capacity of the joint is considered [39], the triaxial stress state of the joint is analytically described and the parameters of the arrangement of loops are described [40], it is proposed to take into account nonlinear dependencies for estimating the deformations of the vertical joint between panels, and the approximating dependence of deformations on shear forces is described [41]. However, these studies concern vertical joints between wall panels. In this article, the area of scientific interest is the development of a design solution for a horizontal joint of floor slabs located in the zone of zero moment.

The proposed solution for connecting precast concrete elements is the use of loop-shaped embedded parts made of flexible loops, which have a number of advantages [42]. Today, there are special embedded loops made of cable or cable reinforcement (Germany, Finland, Estonia, etc.), installed in the form of prefabricated products in the form of compact «boxes». Cable loops are widely used in Europe for connecting precast concrete elements, for example, between wall panels in panel housing construction or when connecting a wall panel to a column in frame-crossbar systems. The use of such parts in joints is a technological solution, saves time in the manufacture of reinforced concrete products and their installation, reduces the amount of metal in the element and does not require the use of assembly welding. There is also no need to plaster the installation sites of embedded parts. However, the application and nature of the work of loop joints of precast concrete structures are not sufficiently studied, and the question of the use of loop-shaped embedded parts in horizontal joints and the determination of their strength and flexibility remains open. Based on the above, the task of modernizing standard solutions for horizontal joints of floors of ringless frames and determining their strength and deformative characteristics is relevant.

\section{Methods}

In order to simplify the installation technology and reduce the complexity of work in the construction of floors according to the UIKSS, CUB systems, in this paper, the use of loopshaped embedded parts in horizontal joints is proposed, the main advantage of this joint is the absence of protruding parts that can be deformed as a result of impact during transportation and installation. A design solution was developed and the stress-strain state of the horizontal floor joint was determined using flexible PFEIFER loops [43] (Fig. 1).

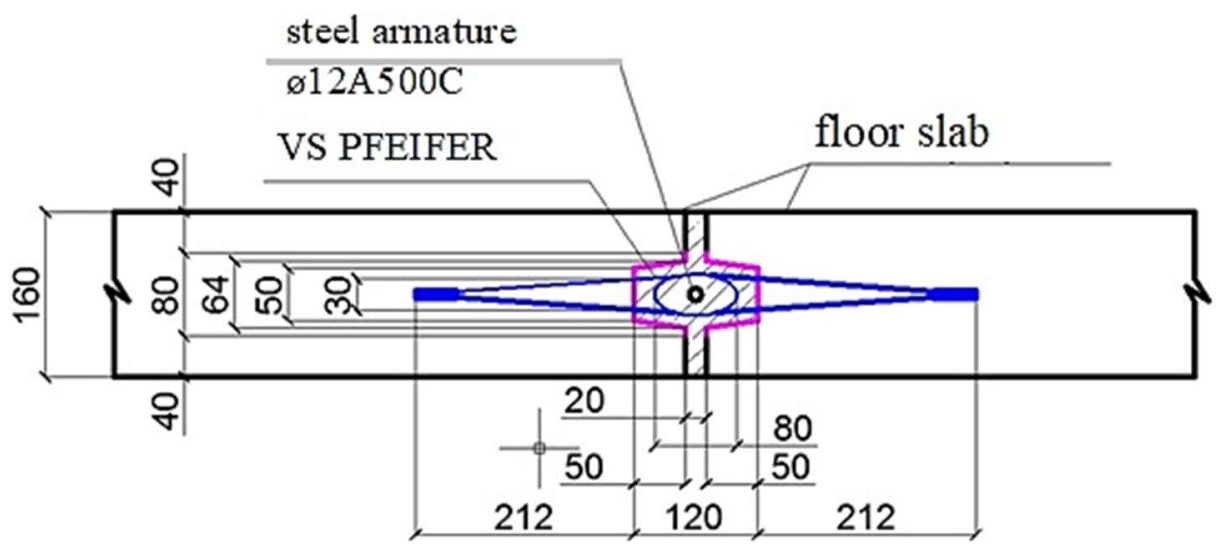

Fig. 1. Structural solution of the joint. Cross-section. 
The developed joint of reinforced concrete floor slabs is formed by reinforced key joints made of loop-shaped embedded parts. To determine the optimal structural solution of the joint, the following parameters were varied: the number of embedded parts located at the joint; the distances between the embedded parts; the concrete grade of the joint. Three variants of the arrangement of embedded parts along the length of the horizontal joint are considered: one embedded part in the middle of the length, two embedded parts at the edges of the joint, two embedded parts in the middle of the joint.

The model for the shear experiment is a joint of two precast reinforced concrete floor panels with a size of $2.98 \times 2.98 \mathrm{~m}$ and a thickness of $160 \mathrm{~mm}$. The joint width is $120 \mathrm{~mm}$. The dowels have dimensions of $120 \times 64 \times 20 \mathrm{~mm}$. The concrete of the floor panels is heavy of class B25, the joint is covered with fine-grained concrete, the class of which varies during the numerical experiment: B20, B25 and B30. The reinforcement rod of a round cross-section with a diameter of $12 \mathrm{~mm}$ is similar to the structural solution of the joint according to the CUB system, taken as a basis. The anchor made of flexible rebar is set by the rope TK $1 \times 19(1+6+12) \varnothing 8.1 \mathrm{~mm}$.

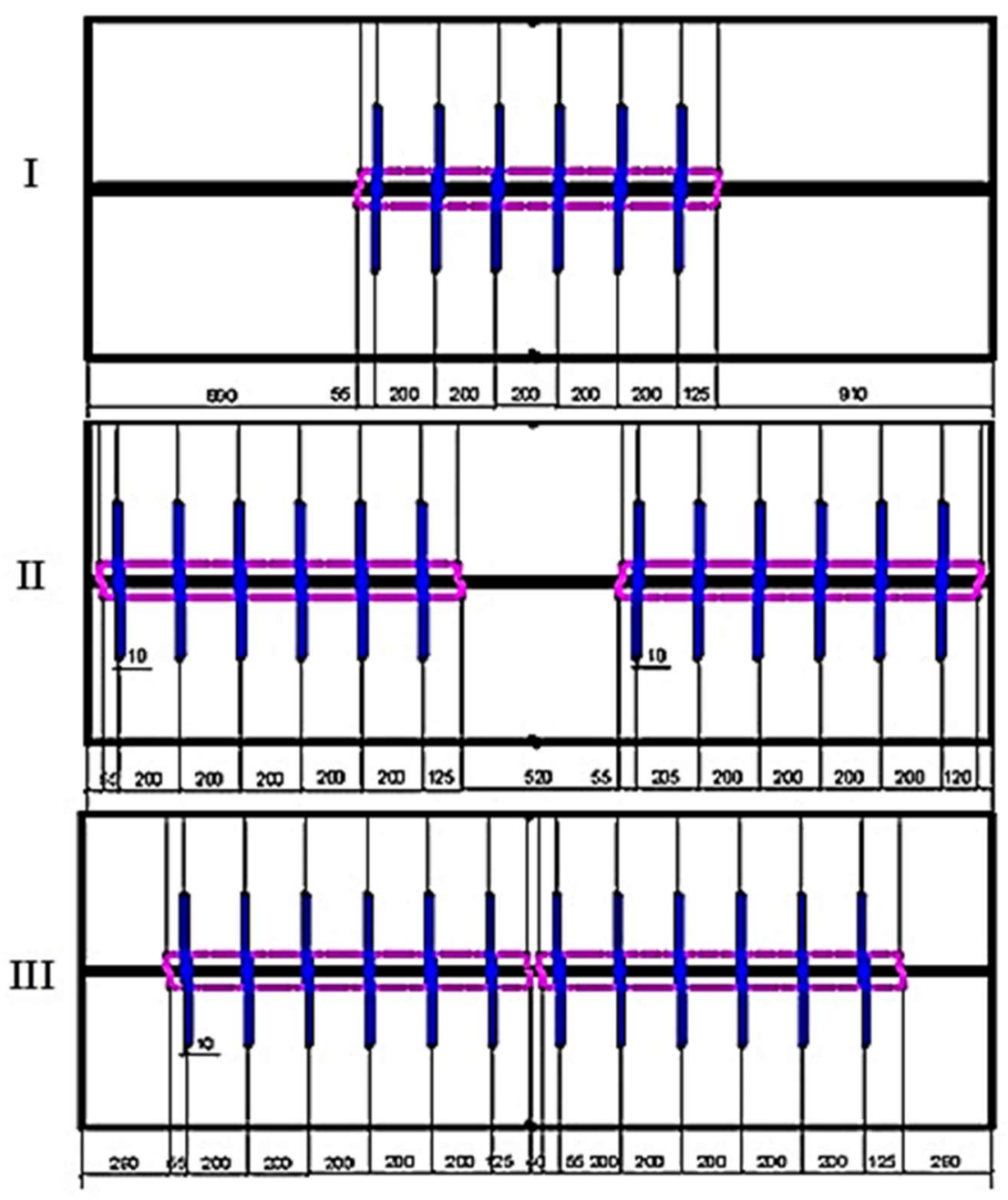

Fig. 2. Structural solution of the joint. Options for placing embedded parts. 
For verification, the data of a full-scale experiment on the study of the VAT of the vertical joint of wall panels with flexible hinges, conducted under the direction of B.S. Sokolov, were used [42]. As a result, it is obtained that the destructive load and the nature of the destruction obtained by numerical modeling are comparable with the data of the physical experiment.

The numerical study of the stress-strain state of the horizontal welded joint of the floor slabs was carried out in the LIRA-SAPR software package. The following model is adopted: the floor slabs and the joint are formed by three-dimensional finite elements with the dimensions of the faces no more than $12 \mathrm{~cm}$, one of the slabs along the contour has rigid connections. For the three-dimensional FE models, the physical and mechanical characteristics of the concrete of the masonry and the concrete of the prefabricated element corresponding to the properties of the materials were used. The rope loops of the embedded parts, as well as the reinforcing rod, are set by the rod end elements. The compliance of the plate interface was modeled by two-node finite elements of the elastic bond (CE55). The load was gradually applied to the end of the left panel of the ceiling.

\section{Results and discussion}

On the basis of numerical modeling of horizontal key joints, their stress-strain state under the perception of shear forces is determined. The nature of the destruction of the samples on the action of the shear force on the horizontal joint is established. The load-bearing capacity of single-spar joints is almost three times lower than that of double-spar joints, and the loadbearing capacity of joints for shear loads practically does not change with an increase in the class of concrete masonry. The moment of crack formation and the nature of destruction of horizontal key joints of floor slabs with flexible transverse reinforcement under the perception of shear forces are established: cracks are formed in the stretched joint zone by the contact of the concrete of the plate and the concrete of the joint, the destruction occurs by the concrete of the masonry. The moment of crack formation increases with an increase in the class of concrete in the joint; the stiffness of the joint is directly proportional to the number of dowels formed by the embedded parts along the length of the joint. The numerical experiment showed that the compliance of a single-spline joint is almost two times higher than the compliance of a double-spline joint. At the same time, it was found that at a greater distance between the dowels (joint option II), the joint flexibility is less than at a close arrangement of the dowels relative to each other (joint option III).

Table 1. Stress-strain state of the joint depending on the class of concrete masonry.

\begin{tabular}{|c|c|c|c|c|c|}
\hline \multirow[b]{2}{*}{$\begin{array}{c}\text { Joint } \\
\text { option }\end{array}$} & \multirow[b]{2}{*}{$\begin{array}{l}\text { Class of } \\
\text { concrete for } \\
\text { masonry }\end{array}$} & \multirow[b]{2}{*}{ Crack load $\mathrm{kN}$} & \multirow[b]{2}{*}{ Breaking load kN } & \multicolumn{2}{|c|}{ Shear compliance, ${ }^{\times} 10^{-6} \mathrm{~m} / \mathrm{kN}$} \\
\hline & & & & $\begin{array}{l}\text { Before } \\
\text { cracking }\end{array}$ & $\begin{array}{l}\text { After the } \\
\text { formation of } \\
\text { cracks }\end{array}$ \\
\hline \multirow{3}{*}{1} & B20 & 17.88 & \multirow{3}{*}{29.8} & 2.16 & 9.63 \\
\hline & B25 & 200 & & 2.14 & 8.83 \\
\hline & B30 & 20.80 & & 2.13 & 8.49 \\
\hline \multirow{3}{*}{2} & B20 & 29.80 & \multirow{2}{*}{80.50} & 1.01 & 4.39 \\
\hline & B25 & 35.76 & & 0.97 & 3.92 \\
\hline & B30 & 41.72 & 92.38 & 0.95 & 3.61 \\
\hline \multirow{3}{*}{3} & B20 & 47.68 & \multirow{3}{*}{74.5} & 1.02 & 5.32 \\
\hline & B25 & 41.72 & & 1.00 & 3.82 \\
\hline & B30 & 59.60 & & 0.98 & 3.69 \\
\hline
\end{tabular}

The breaking loads were determined for all variants of plate coupling: for a single - spar joint, it is $29.8 \mathrm{kN}$, for the two considered variants of a joint with two keys $-80.5 \mathrm{kN}$ (option II) and $74.5 \mathrm{kN}$ (option III). When comparing the load-bearing capacity of two-spar joints and 
the joint according to the CUB system, the comparability of the results obtained is noted. The discrepancy is $4.1 \%$ and $12.55 \%$, respectively. The maximum displacements of the finite elements in the joint are obtained and the values of joint compliance at the stages before and after the crack are calculated. It is noted that the work of the joint under study is similar to the existing joint solution for the UIKSS and CUB systems. The values of the strength and stiffness of the joint models obtained during the numerical study are comparable to the results of previous studies of similar structures [42]. Based on this, we can conclude that the model of the studied coupling of floor slabs is correct and applicable.

According to the results of the numerical study, it is recommended to use the joint option No. II for the design - a two-step joint of reinforced concrete floor slabs with a size of $2980 \times 2980 \mathrm{~mm}$, formed by embedded parts of the Tire VS PFEIFER (VS 50/200) and finegrained concrete of class B25. The embedded parts are located at a distance of $520 \mathrm{~mm}$ from each other with an offset from the ends of the plates at a distance of $40 \mathrm{~mm}$ (to provide an armo-protective layer), the dowels have dimensions of $120 \times 64 \times 20 \mathrm{~mm}$.

The destructive shear load for joint No. II was $80.5 \mathrm{kN}$, the nature of the failure is the formation and development of cracks along the contact of the prefabricated panel and the monolithic concrete of the joint. The moment of crack formation is $35.8 \mathrm{kN}$, which is $44.5 \%$ of the breaking load. The value of the shear compliance of the joint at the elastic stage was $0.97 \cdot 10^{-6} \mathrm{~m} / \mathrm{kN}$, at the stage after the formation of cracks $-3.92 \cdot 10^{-6} \mathrm{~m} / \mathrm{kN}$.

The strength and ductility of joints at the stage before and after the formation of cracks were calculated according to existing methods [44, 45], as well as their comparison with the data of a numerical experiment. According to the results of theoretical calculations and numerical research, it is obtained that the values of compliance during the operation of the joint in the elastic stage before the formation of cracks are close.

In reinforced joints, when cracks appear due to shear forces, the forces are redistributed between the dowels and the rope loops of the joint are «turned on». According to the results of theoretical calculations and numerical experiments, it is obtained that the values of the joint compliance differ by a coefficient approximately equal to the ratio of the initial modulus of elasticity of the concrete of the floor slab and the initial modulus of elasticity of the concrete of the joint masonry. For this stage, in this paper, we propose to use the expression for vertical keyway connections of wall panels, taking into account the coefficient:

$$
\gamma=\frac{E_{b, p}}{E_{b, j}},
$$

$E_{b, p}$ - modulus of elasticity of concrete floor slabs;

$E_{b, j}-$ modulus of elasticity of concrete for joint masonry.

Based on this, it is proposed to improve the existing expression for determining the shear compliance of a loop-shaped weld-free joint by applying the coefficient $\gamma$ in the general compliance formula set out in [44].

The calculated expression for the shear compliance at the stage after the crack is presented in the following form:

where $\lambda_{\tau b}$ - flexibility of the concrete key;

$$
\lambda_{\tau}=\gamma \cdot\left(\lambda_{\tau b}+\lambda_{\tau S}\right)
$$

$\lambda_{\tau_{s}}$ - flexibility of the reinforcement connection.

For the constructions considered in this paper, the coefficient $\gamma$ has the following values:

- when concrete is used for masking the joint, cl. B20: $\gamma=1.36$;

- when concrete is used for masking the joint, cl. B25: $\gamma=1.25$;

- when concrete is used for masking the joint, cl. B30: $\gamma=1.15$.

The value of shear compliance at the stage after the crack is shown in Table 2.

Numerical studies have shown that the load-bearing capacity of the joint increases insignificantly with an increase in the class of concrete masonry, so for further design, it is recommended to use the joint option No. II with fine-grained concrete cl. B25 in the joint. 
Comparison of the calculation results, shown in Table 2 reflects the possibility of applying the proposed calculation expression in assessing the shear compliance of horizontal welded joints of floor slabs with flexible transverse reinforcement. The calculation of strength and load-bearing capacity is proposed to be performed according to the method proposed in the manual for the design of residential buildings [44].

Table 2. Comparison of the values of shear compliance in the horizontal joint of floor slabs at the stage after the formation of cracks.

\begin{tabular}{|c|c|c|c|c|c|}
\hline \multirow{2}{*}{$\begin{array}{c}\text { Joint } \\
\text { option }\end{array}$} & $\begin{array}{c}\text { Class of } \\
\text { concrete for } \\
\text { masonry }\end{array}$ & $\begin{array}{c}\text { by the method } \\
{[44]}\end{array}$ & $\begin{array}{c}\text { by the method } \\
{[45]}\end{array}$ & $\begin{array}{c}\text { based on the results } \\
\text { of a numerical } \\
\text { experiment }\end{array}$ & $\begin{array}{c}\text { by the } \\
\text { formula (2) }\end{array}$ \\
\hline \multirow{3}{*}{ № 1 } & B20 & $6.59 \cdot 10^{-6}$ & $6.03 \cdot 10^{-6}$ & $9.63 \cdot 10^{-6}$ & $8.98 \cdot 10^{-6}$ \\
\cline { 2 - 6 } & B25 & $6.27 \cdot 10^{-6}$ & $5.86 \cdot 10^{-6}$ & $8.83 \cdot 10^{-6}$ & $7.83 \cdot 10^{-6}$ \\
\cline { 2 - 6 } & B30 & $6.03 \cdot 10^{-6}$ & $5.71 \cdot 10^{-6}$ & $8.49 \cdot 10^{-6}$ & $6.96 \cdot 10^{-6}$ \\
\hline \multirow{3}{*}{$№ 2$} & B20 & $3.3 \cdot 10^{-6}$ & $3.02 \cdot 10^{-6}$ & $4.39 \cdot 10^{-6}$ & $4.5 \cdot 10^{-6}$ \\
\cline { 2 - 6 } & B25 & $3.13 \cdot 10^{-6}$ & $2.93 \cdot 10^{-6}$ & $3.92 \cdot 10^{-6}$ & $3.91 \cdot 10^{-6}$ \\
\cline { 2 - 6 } & B30 & $3.0 \cdot 10^{-6}$ & $2.85 \cdot 10^{-6}$ & $3.61 \cdot 10^{-6}$ & $3.46 \cdot 10^{-6}$ \\
\hline \multirow{3}{*}{ № 3 } & B20 & $3.3 \cdot 10^{-6}$ & $3.02 \cdot 10^{-6}$ & $5.32 \cdot 10^{-6}$ & $4.5 \cdot 10^{-6}$ \\
\cline { 2 - 6 } & B25 & $3.13 \cdot 10^{-6}$ & $2.93 \cdot 10^{-6}$ & $3.82 \cdot 10^{-6}$ & $3.91 \cdot 10^{-6}$ \\
\hline & B30 & $3.0 \cdot 10^{-6}$ & $2.85 \cdot 10^{-6}$ & $3.69 \cdot 10^{-6}$ & $3.46 \cdot 10^{-6}$ \\
\hline
\end{tabular}

The maximum discrepancy between the values of the shear compliance of the joint according to the formula proposed in this paper and the numerical experiment was $22.04 \%$. This discrepancy is acceptable, since it does not lead to a significant change in the forces in the elements. According to experimental data, for vertical joints of prefabricated elements of a similar design $[46,47]$, it was noted that a $25 \%$ reduction in joint flexibility leads to an increase in forces by $10.7 \%$. When comparing the values of the compliance of the numerical model of the joint according to the CUB-system and the joints No. II and No. III considered in the work, the differences in the values were $8 \%$ - for the stage of elastic work, $9 \%$ - in the stage after the formation of cracks. These values indicate the possibility of comparing the existing joint design with the proposed ones. The reliability of the model under study is confirmed by comparing the data obtained with the results of previous experiments, as well as by the comparability of the results of the numerical study with theoretical calculations.

Numerical simulations were used to obtain data on the stress-strain state of various variants of horizontal joints using flexible loops. According to the results of the comparison of the stress-strain state of the joint models for the CUB and UIKSS-systems and the proposed models of the two-step joint, a similar nature of work is noted, which is confirmed by the data of field experiments and allows us to consider the proposed solutions adequate. The closest approach to the existing solution is joint No. III with fine-grained concrete of class B25 in the joint. However, the parameters (moment of cracking, breaking load, stiffness) of the joint option No. II with the same class of concrete in the joint are higher. Since the load-bearing capacity of the joint increases slightly with an increase in the class of concrete of masonry, it is recommended to use the joint option No. II with fine-grained concrete of class B25 in the joint.

\section{Conclusion}

Based on the results of this work, it can be concluded that it is possible and expedient to use embedded parts made of flexible PFEIFER loops in the horizontal joints of floor slabs in the design of residential and administrative buildings with the ringless frame systems UIKSS, CUB. Further development of the topic of this work is possible in the field of studying the 
influence of the work of PFEIFER embedded parts in the joints of floor slabs on the overall VAT of the building frame, on the possibility of using these embedded parts in construction in areas with seismic activity. Using the results of Russian and foreign researchers on the compliance of reinforcement in vertical non-welded loop-shaped joints, it is possible to transform the analytical expression (2) and obtain data on the operation of joints, taking into account the residual load-bearing capacity. Thus, the data obtained in the presented work opens up a wide range of research in the direction of modernization of existing design solutions.

\section{References}

1. V. Lyublinsky, M. Tomina. Experimental study of the strength and suppleness of a vertical welded joint, Systems. Methods. Technologies 3 (39), 154-158 (2018). DOI: 10.18324/2077-5415-2018-3-154-158.

2. B. Sokolov, E. Troshkov. Reconstruction and construction of buildings of light industry with bearing system «UIKSS», Izvestiya Vysshikh Uchebnykh Zavedenii, Seriya Teknologiya Tekstil'noi Promyshlennosti 2, (2017).

3. S. Srisangeerthanan, M.J. Hashemi, P. Rajeev, E.F. Gad, S. Fernando. Review on Diaphragm Behaviour and Connections for Multi-Story Modular Buildings, Australasian Structural Engineering Conference, (2018).

4. A.I. Sadykova, R.Kh. Akhtyamova. Resource-saving principles of modernization in the architecture of mass housing, Izvestiya KGASU 1 (47), 92-99 (2019).

5. S.V. Nikolaev. Updating of the country's housing stock on the basis of large-panel, Housing construction 3, 3-7 (2018).

6. J.P. Vella, R.L. Vollum, A. Jackson. Flexural behaviour of headed bar connections between precast concrete panels, Construction and Building Materials, (2017). DOI: 10.1016/j.conbuildmat.2017.07.146.

7. A. Baghdadi, M. Heristchian, H. Kloft. Connections placement optimization approach toward new prefabricated building systems, Engineering Structures 233, (2021). DOI: 10.1016/j.engstruct.2020.111648.

8. S.J. Menegon, J.L. Wilson, N.T.K. Lam, E.F. Gad. Experimental testing of innovative panel-to-panel connections for precast concrete building cores, Engineering Structures 207, (2020). DOI: 10.1016/j.engstruct.2020.110239.

9. I. Hollý, I. Harvan. Connections in precast concrete elements, Key Engineering Materials 691, (2016). DOI: 10.4028/www.scientific.net/KEM.691.376.

10. S.M.A. Inamdar. Joints and Connections in Precast Concrete Buildings, International Journal of Science and Research (IJSR) 7 (6), (2018).

11. L. Storozhenko, D. Yermolenko, A. Nyzhnyk, I. Tegza. New design decisions of prefabricated girderless floors of multi-storeyed buildings, MATEC Web of Conferences 116, (2017). DOI: 10.1051/matecconf/201711602032.

12. Patent 141473 of the Russian Federation, IPC E04B. Universal industrial frame construction system-Tatarstan / Sokolov B.S. Publ. 10.06.2014. Bank of Patents. Access mode: http://bankpatentov.ru/ node/597203.

13. Unified system of prefabricated monolithic ringless frame CUBE 2.5, TSNIIPI Monolit, Moscow, 1990.

14. S. Singhal, A. Chourasia, J. Parashar. Anchorage behaviour of headed bars as connection system for precast reinforced concrete structural components, Structures 27, (2020). doi: 10.1016/j.istruc.2020.07.043.

15. B. Joergensen Henrik, S.G. Hansen. Experimental investigation on the shear capacity of $R C$ beams with curtailed reinforcement, Engineering Structures 169, (2018). DOI: 10.1016/j.engstruct.2018.05.025.

16. A. Rosyidah, I.K. Sucita, P. Sukarno, S.R.P. Sari, C. Sari. Bond strength of bar using 
grouting for precast concrete connection, Applied Research on Civil Engineering and Environment (ARCEE) 1 (01), (2019). DOI: 10.32722/arcee.v1i01.2311.

17. S.G. Hansen, N.E. Abildgaard, H.B. Joergensen. Strengthening strategy for the shear capacity in existing concrete structures, Structural Engineering International 28 (4), (2018). DOI: 10.1080/10168664.2018.1453765.

18. A.A. Semendary, W.K. Hamid, E.P. Steinberg, I. Khoury. Shear friction performance between high strength concrete (HSC) and ultra high performance concrete (UHPC) for bridge connection applications, Engineering Structures 205, (2020). DOI: 10.1016/j.engstruct.2019.110122.

19. G. Metelli, N. Bettini, G. Plizzari. Experimental and numerical studies on the behaviour of concrete sandwich panels, European Journal of Environmental and Civil Engineering 15 (10), (2011). DOI: 10.1080/19648189.2011.9723354.

20. J. Qian, X. Song, B. Feng, Y. Zhang, H. Wang. Experimental study and finite element analysis of seismic behavior of sprayed concrete sandwich shear walls, Jianzhu Jiegou Xuebao Journal of Building Structures 34 (10), (2013).

21. M. Serpilli, F. Clementi, S. Lenci. An experimental and numerical study on the in-plane axial and shear behavior of sprayed in-situ concrete sandwich panels, Engineering Structures 232, (2021). DOI: 10.1016/j.engstruct.2020.111814.

22. M. Leblouba, S. Barakat, M.S.A. Ahmed, S. Al-Toubat. Shear strength at the interface of precast bridge concrete decks and girders subjected to cyclic loading with varying speeds, Engineering Structures 196, (2019). DOI: 10.1016/j.engstruct.2019.109296.

23. J. Sagaseta, P. Francis. Out-of-plane shear strength of steel-concrete sandwich panels, (2018). DOI: 10.35789/fib.bull.0085.ch14.

24. B. Dal Lago, F. Biondini, G. Toniolo. Experimental tests on multiple-slit devices for precast concrete panels, Engineering Structures 167, (2018). DOI: 10.1016/j.engstruct.2018.04.035.

25. I.N. Psycharis, H.P. Mouzakis. Shear resistance of pinned connections of precast members to monotonic and cyclic loading, Engineering Structures 41. DOI: 10.1016/j.engstruct.2012.03.051.

26. S. Srisangeerthanan, M.J. Hashemi, P. Rajeev, E. Gad, S. Fernando. Numerical study on the effects of diaphragm stiffness and strength on the seismic response of multi-story modular buildings, Engineering Structures 163, (2018). DOI: 10.1016/j.engstruct.2018.02.048.

27. P. Seifi, R.S. Henry, J.M. Ingham. Panel connection details in existing New Zealand precast concrete buildings, Bulletin of the New Zealand Society for Earthquake Engineering 49 Iss. 2, (2016). DOI: 10.5459/bnzsee.49.2.190-199.

28. R.A. Kayumov, I.Z. Muhamedova, V.O. Krasilnikov, B.F. Tazyukov. Development of the design procedure for structural elements of multi-storey residential building for durability, Izvestiya KGASU 4 (42), 167-173 (2017).

29. K. Hodicky, G. Sopal, S. Rizkalla, T. Hulin, H. Stang. Experimental and Numerical Investigation of the FRP Shear Mechanism for Concrete Sandwich Panels, Journal of Composites for Construction 19 (5), (2015). DOI: 10.1061/(asce)cc.1943-5614.0000554.

30. S. May, A. Schumann, M. Curbach. Shear strengthening of structures with carbon reinforced concrete, Proceedings of the $12^{\text {th }}$ Fib International PhD Symposium in Civil Engineering, (2018).

31. Y.O. Özkılıç, Ş. Yazman, C. Aksoylu, M.H. Arslan, L. Gemi. Numerical investigation of the parameters influencing the behavior of dapped end prefabricated concrete purlins with and without CFRP strengthening, Construction and Building Materials 275, (2021). DOI: 10.1016/j.conbuildmat.2020.122173.

32. J.P. Vella, R. Vollum, A. Jackson. Headed bar connections between precast concrete panels loaded in bending High Tech Concrete: Where Technology and Engineering Meet, Proceedings of the 2017 Fib Symposium, (2017). DOI: 10.1007/978-3-319-59471-2_115.

33. J.P. Vella, R.L. Vollum, A. Jackson. Investigation of headed bar joints between precast 
concrete panels, Engineering Structures 138, (2017). DOI: 10.1016/j.engstruct.2017.02.018.

34. J. Daniel Ronald Joseph, J. Prabakar, P. Alagusundaramoorthy. Experimental study on the flexural behavior of insulated concrete sandwich panels with wires as shear connectors, Alexandria Engineering Journal 58 (3), (2019). DOI: 10.1016/j.aej.2019.08.005.

35. J.P. Vella, R.L. Vollum, R. Kotecha. Headed Bar Connections Between Precast Concrete Elements: Design Recommendations and Practical Applications, Structures 15, (2018). DOI: 10.1016/j.istruc.2018.06.008.

36. J. Di, B. Han, F. Qin. Investigation of U-bar joints between precast bridge decks loaded in combined bending and shear, Structures 27, (2020). DOI: 10.1016/j.istruc.2020.05.041.

37. B. Joergensen Henrik, L. Christensen, J. Bendixen. Experimental study on the tensile capacity of bridge deck loop connections with shear keys FIB 2018, Proceedings for the 2018 Fib Congress: Better, Smarter, Stronger (2019).

38. Henrik Broener Joergensen, L.C. Hoang. Strength of loop connections between precast bridge decks loaded in combined tension and bending, Structural Engineering International: Journal of the International Association for Bridge and Structural Engineering (IABSE) 25 (1), 71-80 (2015). DOI: 10.2749/101686614X14043795570697.

39. Z.T. Deger, C. Basdogan. Empirical expressions for deformation capacity of reinforced concrete structural walls, ACI Structural Journal 116 (6), (2019). DOI: $10.14359 / 51716806$.

40. Henrik Broener Joergensen. The influence of tolerances on the load bearing capacity of looped wire rope connections, Proceedings of the Fib Symposium 2019: Concrete Innovations in Materials, Design and Structures, (2019).

41. V.A. Lyublinskiy. To Test Vertical Welded Butt Joints of Panel Buildings, Building and Reconstruction 85 (5), 17-22 (2019). DOI: 10.33979/2073-7416-2019-85-5-17-22.

42. B.S. Sokolov, Yu.V. Mironova. Strength and flexibility of vertical joints of wall panels using flexible loops, Housing construction 5, 60-62 (2014).

43. Catalog PFEIFER-Memmingen 02, 26 (2017).

44. Manual for the design of residential buildings 1989 Issue 3 part 1 Constructions of residential buildings (to SNiP 2.08.01-85), 305.

45. E. Gorachek, V.I. Lishak, D. Pume. Strength and rigidity of butt joints of panel structures, The experience of the USSR and the Czech SSR Stroyizdat, 192 (1980).

46. I.S. Derbentsev. Test results of full-scale samples of keyed joints of panels of large-panel buildings with flexible connections, Nauchny poisk: materials of the second scientific conference of postgraduates and doctoral students. Technical sciences. SUSU Publishing Center 1, 72-76 (2010).

47. I.S. Derbentsev. Bearing capacity and deformability of key joints with loop flexible connections in joints of large-panel multi-storey buildings, Construction-formation of the life environment: collection of reports of the $16^{\text {th }}$ international interuniversity scientific and practical conference, 346-352 (2013). 